\title{
Thermal Cracking and Heat Sink Capacity of Aviation Kerosene Under Supercritical Conditions
}

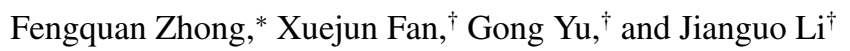 \\ Chinese Academy of Sciences, Beijing 100190, People's Republic of China \\ and \\ Chih-Jen Sung \\ University of Connecticut, Storrs, Connecticut 06269
}

\begin{abstract}
DOI: $\underline{10.2514 / 1.51399}$
Thermal cracking and endothermicity of China No. 3 aviation kerosene were studied experimentally under supercritical conditions relevant to regenerative cooling systems for scramjet applications. A multiple-stage heating system with reaction products collection was used that can achieve a fuel temperature range of 780-1050 K, a pressure range of 3-4.5 $\mathrm{MPa}$, and a residence time range of $0.6-3 \mathrm{~s}$. The chemical heat sink was determined through a control volume analysis of the fuel flow. Compositions of the cracked gaseous and liquid products were analyzed via gas chromatography. Based on the results of fuel conversion, the temperature range for the active cracking was observed to be approximately 800-1000 K, beyond which the cracking approaches completion. It was also found that the variation of the chemical heat sink with temperature can be nonmonotonic and a maximum endothermicity was seen to occur in the temperature range of $900-960 \mathrm{~K}$, depending on the residence time. For the current operation conditions, the maximum chemical heat sink reached $0.5 \mathrm{MJ} / \mathrm{kg}$ at a fuel conversion of $45 \%$. Composition analysis of the gaseous product indicated that the saturated hydrocarbons such as methane became dominant as temperature was increased. On the other hand, the major compositions of the liquid product were benzene-based and naphthalene-based hydrocarbons.
\end{abstract}

\section{Introduction}

$\mathbf{F}$ OR hypersonic applications, active cooling using onboard hydrocarbon fuel is considered to be one of the most effective ways for thermal protection. Before injection into combustor, the fuel flows through cooling channels along the engine liner, carrying away heat from the wall via heat convection and endothermic reactions. For high Mach number flight, the sensible heat of the fuel is no longer adequate for the cooling requirement and an extra heat sink is required, which can be provided by endothermic cracking of the fuel at high temperatures $[1,2]$.

Thermal cracking of hydrocarbon and its applications have been studied broadly in petrochemical industry [ $\underline{3}]$, of which the working pressure is near atmospheric pressure and much lower than the pressures for hypersonic application. For example, the typical pressure in the cooling channel of a Mach-6 scramjet is approximately 4-7 MPa, higher than the critical pressure ( $\sim 2 \mathrm{MPa})$ for most liquid hydrocarbons. Compared with low pressure cracking, highpressure situations are expected to lead to lower fuel conversion, larger percentage of paraffin products, and less endothermicity, while keeping other operating conditions the same. Hence, it is imperative to study characteristics of thermal cracking of hydrocarbons and the associated endothermicity under supercritical pressures.

Lander and Nixon [1] discussed properties and possible cooling applications of thermal and catalytic cracking of various hydro-

Presented as Paper 2009-5267 at the 45th AIAA/ASME/SAE/ASEE Joint Propulsion Conference and Exhibit, Denver, CO, 2-5 August 2009; received 30 June 2010; revision received 1 October 2010; accepted for publication 2 October 2010. Copyright (๑) 2010 by the American Institute of Aeronautics and Astronautics, Inc. All rights reserved. Copies of this paper may be made for personal or internal use, on condition that the copier pay the $\$ 10.00$ percopy fee to the Copyright Clearance Center, Inc., 222 Rosewood Drive, Danvers, MA 01923; include the code 0887-8722/11 and $\$ 10.00$ in correspondence with the CCC.

*Associate Professor, Key Laboratory of High Temperature Gas Dynamics, Institute of Mechanics; fzhong@imech.ac.cn (Corresponding Author).

†Professor, Key Laboratory of High Temperature Gas Dynamics, Institute of Mechanics.

†Professor, Department of Mechanical Engineering. Associate Fellow AIAA. carbons. They found that the chemical heat sink due to thermal cracking did not always increase with temperature. For JP-7 fuel, the maximum endothermicity was approximately $0.72 \mathrm{MJ} / \mathrm{kg}$ at a $60 \%$ conversion. Edwards and Anderson [4] studied thermal cracking of JP-7 fuel through a heated tube system and found that the endothermicity of JP-7 was on the order of $0.7 \mathrm{MJ} / \mathrm{kg}$, which is much smaller than the theoretical value $(3.5 \mathrm{MJ} / \mathrm{kg}$ ) if assuming the cracking products were all alkenes such as ethylene. Based on the results of gas and mass chromatograph, they [4] argued that the reduction in the endothermicity was caused by significant formation of saturated hydrocarbons. Edwards [5] further showed that the flow reactor residence time is critical for the endothermic property of the cracking mixture, since long residence time would form products approaching the equilibrium products such as light saturated hydrocarbons and the overall reactions become exothermic. As discussed in $[\underline{5}, \underline{6}]$, the effect of residence time could be easily characterized by plotting olefin/paraffin ratio (an indicator of endothermicity) as a function of residence time. In general, shorter residence time corresponds to larger olefin/paraffin ratio, thereby leading to a more endothermic cracking process. Stewart et al. [7] studied pyrolysis of $n$-decane and decalin at temperatures of $700-810 \mathrm{~K}$ and subcritical/ supercritical pressures of $0.2-10 \mathrm{MPa}$. It was found that the main products of supercritical pyrolysis were different from those from subcritical pyrolysis, and high pressure can promote the $\mathrm{C}_{6}$ to $\mathrm{C}_{5}$ ring contraction. Fan et al. [ 8 ] investigated supersonic combustion properties of thermally cracked China No. 3 aviation kerosene in a supersonic model combustor. Higher combustion efficiency was found for the cracked kerosene since the cracking products consisting of small molecules such as ethylene and hydrogen that can assist fuel/air mixing and combustion. It is worth mentioning that for most of previous studies, the fuel temperature varied along the reaction section of the heated tube and at the same time, there existed a significant temperature difference between the fuel and the wall, i.e., a somewhat large temperature gradient. Because of the axial and radial temperature gradients within the tube, an accurate cracking temperature is hard to define and the cracking process is coupled with convective heat transfer causing difficulties in interpreting the experimental results. Therefore, one of the objectives of this paper is to obtain a relatively uniform fuel temperature distribution along the reaction section as well as a negligible heat convection effect (i.e., 